\title{
MODELAGEM HIDROLÓGICA DETERMINÍSTICA E ESTOCÁSTICA APLICADA À REGIÃO HIDROGRÁFICA DO XINGU - PARÁ
}

\author{
EDMUNDO WALLACE MONTEIRO LUCAS ${ }^{1}$, FRANCISCO DE ASSIS SALVIANO DE SOUSA ${ }^{2}$, \\ FABRICIO DANIEL DOS SANTOS SILVA ${ }^{1}$, PAULO SERGIO LUCIO ${ }^{3}$
}

\author{
${ }^{1}$ Instituto Nacional de Meteorologia (INMET), Brasília - DF \\ ${ }^{2}$ Unidade Acadêmica de Ciências Atmosféricas, Centro de Tecnologia e Recursos Naturais, Universidade \\ Federal de Campina Grande (UACA/CTRN/UFCG), Campina Grande - PB, \\ ${ }^{3}$ Departamento de Estatística, Universidade Federal do Rio Grande do Norte (UFRN) \\ edmundo.lucas@inmet.gov.br, fassis@dca.ufcg.edu.br, \\ fabricio.silva@inmet.gov.br,pslucio@ccet.ufrn.br
}

Recebido Novembro 2007 - Aceito Março 2009

\section{RESUMO}

A modelagem hidrológica é uma importante ferramenta no planejamento e gerenciamento de programas de recursos hídricos de bacias hidrográficas. Neste trabalho, foi aplicado o modelo hidrológico determinístico mensal de dois parâmetros e o modelo estocástico, ARIMA, para simular a vazão mensal das sub-bacias da região hidrográfica do Xingu no Estado do Pará. O objetivo principal foi simular a vazão mensal através dos modelos e comparar os seus resultados. O modelo hidrológico determinístico aplicado possui uma estrutura simples e apresentou bons resultados, porém mostrou-se muito sensível a eventos extremos de precipitação. O modelo estocástico ARIMA, conseguiu capturar a dinâmica das séries temporais, apresentando resultados muito satisfatórios na simulação da vazão mensal nas estações da bacia. Ambos os modelos devem ser aplicados com cautela no período chuvoso, onde ocorrem os eventos extremos de precipitação e consequentemente vazões de pico.

Palavras-chave: Bacias Hidrográficas, Modelos hidrológicos, Vazão.

\begin{abstract}
DETERMINISTIC AND STOCHASTIC HYDROLOGICAL MODELING APPLIED TO THE XINGU RIVER BASIN - PARÁ

Hydrologic modeling is an important tool for the planning and management of water resources use in river basins. In this work, a two-parameter monthly deterministic hydrologic model and the stochastic model, ARIMA, were applied to simulate the monthly runoff of the Xingu river basin in the State of Pará. The main objective of this work is to simulate the monthly runoff using the two models and to compare their results. The applied hydrological deterministic model has a simple structure and presented good results, but seems to be very sensitive to extreme precipitation events. The stochastic model ARIMA was able to capture the dynamic of the temporal series, presenting very satisfactory results for the simulation of the monthly runoff at the basin stations. Both models should be applied with caution during the rainy season, when extreme precipitation events and consequently peaks of runoff occur.
\end{abstract}

Keywords: River basin, Hydrological Modeling, Runoff. 


\section{INTRODUÇÃO}

Para previsão da distribuição dos recursos hídricos sob diferentes condições, costuma-se empregar modelos hidrológicos mensais para a conversão de chuva em vazão. Geralmente, os modelos hidrológicos mensais são aplicados em três campos: informações preliminares para construção de reservatórios de água; estudos de impactos das mudanças climáticas em bacias hidrográficas e avaliação sazonal de suprimento e demanda de água para irrigação. A vantagem dessa escala temporal é que a formulação do modelo é mais simples, e o número de parâmetros é menor do que em modelos hidrológicos em base diária.

Em geral, a previsão hidrológica pode ser feita principalmente através de dois tipos de modelos: os modelos determinísticos chuva-vazão e os modelos estocásticos. Os primeiros procuram representar os processos físicos de transformação de chuva em vazão, enquanto que os modelos estocásticos baseiam-se na análise da estrutura de dependência temporal das séries de afluências.

O objetivo deste trabalho é simular a vazão média mensal das sub-bacias da região hidrográfica do Xingu no Estado do Pará, utilizando dois modelos hidrológicos com base mensal: determinístico (chuva-vazão) e outro estocástico, denominado ARIMA “Auto Regressive Integrated Moving Average". Essa região destaca-se pelo alto potencial hidrelétrico devido ao seu grande volume de água e relevo acidentado, propiciando condições ideais para geração de energia, podendo citar o estudo de implantação da usina hidrelétrica de Belo Monte realizado pela Eletrobrás (Centrais Elétricas Brasileiras S/A) com parcerias de empresas privadas, segundo o estudo a usina deverá gerar 11.187 mil megawatts (MW), e terá um reservatório de $440 \mathrm{~km}^{2}$ quando concluída.

\subsection{Modelos Hidrológicos}

Um modelo hidrológico permite equacionar os processos, representar, entender e simular o comportamento hidrológico de uma bacia hidrográfica (Tucci, 1998). Modelos hidrológicos podem ser classificados por diferentes aspectos tais como: tipos de variáveis utilizadas no modelo (estocástico ou determinístico), tipo de relação entre essas variáveis (empírico ou conceitual), a forma de representar os dados (discretos ou contínuos), a existência ou não de relações espaciais (pontuais ou distribuídos) e a existência de dependência temporal (estatísticos ou dinâmicos).

Um dos primeiros trabalhos a discutir sobre a estrutura de modelos hidrológicos chuva-vazão e sua perspectiva para o futuro foi feito por Todini (1988). Esse autor faz um histórico dos modelos desenvolvidos até então, na oportunidade verificou que os modelos apresentavam muitos parâmetros, geralmente incorporavam muitos erros nos resultados e na descrição de cada um dos processos envolvidos em toda extensão da bacia.

Galvincio et al. (2002), simularam a vazão mensal na bacia hidrográfica do alto São Francisco, por meio de dois modelos estocásticos: auto regressivo (AR) e medias móveis (MA) de ordem 1, no período de 1978 a 1983. Os autores observaram que o modelo MA não representou bem os valores extremos para algumas estações, já o modelo AR representou bem os valores extremos das vazões mensais; porém não simulou de forma adequada os valores intermediários de vazões. Em ambos os modelos a persistência da série histórica foi preservada.

Xiong \& Guo (1999) desenvolveram um modelo mensal de dois parâmetros para simular vazões em 70 sub-bacias no sul da China e compararam seus resultados com os resultados de um modelo de quatro parâmetros de Guo $(1992,1995)$ aplicado em oito dessas 70 sub-bacias. Os autores obtiveram bons resultados segundo os termos do critério de eficiência de Nash-Sutcliff e concluíram que o modelo de dois parâmetros, apesar de apresentar uma estrutura mais simples, simulou muito bem as vazões mensais e pode ser aplicado a programas de planejamento de recursos hídricos e estudos de impactos climáticos em regiões úmidas e semi-úmidas.

\subsection{Teste de modelos e otimização de parâmetros}

Para desenvolver um modelo hidrológico completo, muitos dados de diferentes bacias são necessários para testar o desempenho desse modelo. Os testes normalmente incluem dois passos: calibração e validação. Calibração se refere ao processo de usar a primeira parte da série de dados, para encontrar os melhores valores dos parâmetros desconhecidos do modelo através de otimização. Validação refere-se ao processo de usar a segunda parte da série de dados, para verificar a persistência do desempenho do modelo, que opera com os valores dos parâmetros obtidos no período de calibração.

Muitos testes foram desenvolvidos para avaliar o desempenho de modelos hidrológicos. Um dos trabalhos pioneiros foi desenvolvido por Nasch \& Sutcliff (1970), onde apresentaram critérios para avaliar o desempenho do modelo. Para os autores, embora a simplificação da operação da bacia hidrográfica seja necessária, principalmente em termos de variabilidade espacial, o modelo deve refletir a base física, considerando que uma ou mais funções do modelo podem ser isoladas e parâmetros relevantes otimizados. Desse modo, o modelo poderá ser mais eficiente do que se fosse otimizado como um todo.

Perrin et al. (2003), discutem a melhoria na aplicação de modelos hidrológicos, e destacam dois problemas iniciais: estrutura do modelo e o conjunto de funções matemáticas 
aplicadas. Para eles, ambos devem representar o comportamento da bacia e o nível de complexidade na estrutura do modelo para garantir o melhor resultado. Perin et al. (2001), definem muito bem a estrutura dos modelos (robustez, versatilidade, etc.) e afirmam que a qualidade da metodologia dos modelos chuva - vazão está ligada essencialmente a sua estrutura.

\section{MATERIAL E MÉTODOS}

\subsection{Características gerais da região hidrográfica do Xingu}

A bacia Amazônica é a maior bacia hidrográfica do

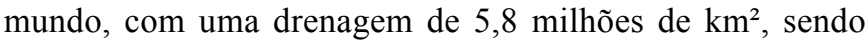
3,9 milhões no Brasil, dividida em 10 sub-bacias (10 a 19), conforme a divisão do Conselho Nacional de Recursos Hídricos (CNRH), na qual se destaca a região hidrográfica do Xingu (bacia 18), tanto pela sua área de aproximadamente $530 \mathrm{mil}$ $\mathrm{km}^{2}$, pertencentes aos Estados do Pará e Mato Grosso, onde está localizada a nascente do rio principal, o Xingu, na serra do Roncador, quanto pelo seu potencial hidrelétrico estimado de 5.143 MW. A área pertencente ao Estado do Pará (Figura 01), ocupa aproximadamente $315 \mathrm{mil} \mathrm{km}^{2}$, correspondendo a $25 \%$ da área do Estado. Os principais municípios localizados na região são: Altamira, São Félix do Xingu, Senador José Porfírio, Vitória do Xingu, Brasil Novo, Placas e partes do município de Medicilândia e Anapú. Os principais cursos d'água formadores dessa bacia, no Pará, são os rios Xingu, Irirí, Curuá, Fresco, Bacajá, Caeté, Ximxim e Chiche.

De acordo com o Instituto Nacional de Meteorologia, baseado nas "Normais Climatológicas - 1961-1990" (INMET, 2008), a climatologia das temperaturas do ar na região, apresenta

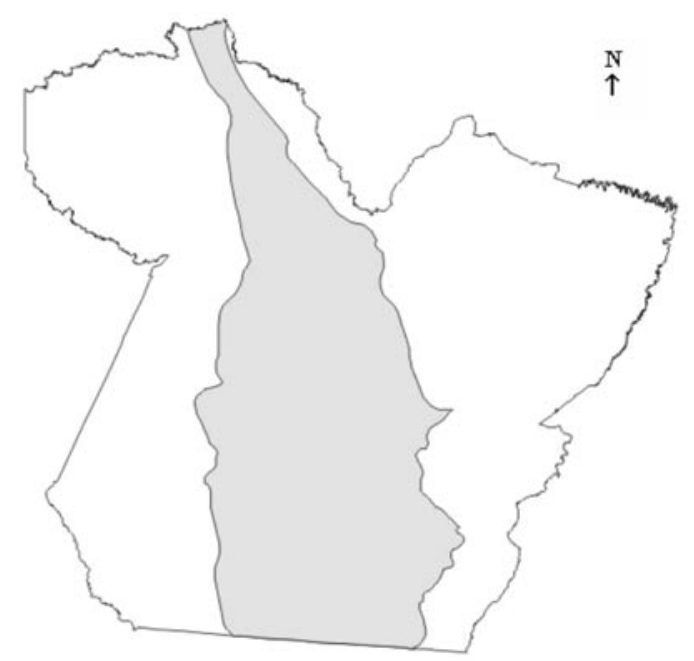

Figura 1 - Localização geográfica da região hidrográfica do Xingu no Estado do Pará valores de temperatura média compensada anual entre 24 e 28 ${ }^{\circ} \mathrm{C}$, temperatura máxima anual entre 28 e $30^{\circ} \mathrm{C}$ e temperatura mínima anual entre 18 e $24^{\circ} \mathrm{C}$. Na parte sul da região verifica-se as maiores amplitudes térmicas anuais. A umidade relativa do ar apresenta valores acima de $80 \%$ em quase todos os meses do ano.

Lucas et al. (2006) ao estudarem a regionalização e distribuição espacial e temporal da precipitação na bacia hidrográfica do Xingu/PA, verificaram que a precipitação varia de 1500 a $2500 \mathrm{~mm}$. ano $^{-1}$, aproximadamente, sendo que nas partes norte e sudoeste da bacia, ocorrem as maiores magnitudes de chuvas, principalmente causadas pela atuação dos sistemas atmosféricos conhecidos como Zona de Convergência Intertropical (ZCIT) e Zona de Convergência do Atlântico Sul (ZCAS), respectivamente. A bacia em estudo apresenta três estações de chuvas distintas e bem definidas: a estação chuvosa, de dezembro a maio, a estação seca, de junho a setembro e uma de transição seca-chuva, em outubro e novembro.

\subsection{Dados Utilizados}

Foram selecionadas para este trabalho, oito estações com dados consistidos mensais de chuvas e vazões, localizadas na região hidrográfica do Xingu/PA (Figura 2) a partir do Inventário das Estações Fluviométricas e Pluviométricas da Agência Nacional de Águas (ANA, 2006). Informações sobre a área drenada em cada estação e o período de dados estão descritas na Tabelas 1 .

Tabela 1 - Dados das estações pluviométricas e fluviométricas da região hidrográfica do Xingu/PA

\begin{tabular}{lcc}
\hline Estação & $\begin{array}{c}\text { Área de } \\
\text { Drenagem }\left(\mathrm{Km}^{2}\right)\end{array}$ & $\begin{array}{c}\text { Período de Dados } \\
\text { Altamira }\end{array}$ \\
Arapari & 146203 & $01 / 1975$ à $12 / 2005$ \\
Belo Horizonte & 277265 & $06 / 1972$ à $12 / 2005$ \\
Boa Esperança & 42275 & $05 / 1976$ à $12 / 1997$ \\
Cajueiro & 34693 & $01 / 1976$ à $12 / 2002$ \\
Pedra do Ó & 123827 & $09 / 1976$ à $12 / 2002$ \\
São Felix do Xingu & 250269 & $07 / 1975$ à $12 / 1996$ \\
Uruara & 2628 & $01 / 1978$ à $12 / 2005$ \\
\hline
\end{tabular}

Os dados de temperaturas do ar médias mensais, para a estimativa da evapotranspiração potencial mensal, foram obtidos a partir de um conjunto de reanálises do National Centers for Environment Prediction/National Center for Atmospheric Research (NCEP/NCAR), em grades de $2,5^{\circ} \times 2,5^{\circ}$, para o 
período de 1975 a 2005. Uma discussão e avaliação da qualidade desses dados foi feita por Kalnay et al. (1996) e por Kistler et al. (2001).

Os dados de vazões mensais observadas nas estações fluviométricas apresentadas serão divididos em dois períodos para o desenvolvimento dos modelos propostos: um período com cerca de $80 \%$ dos dados, no início da série histórica, para ajuste, calibração, otimização dos parâmetros e simulação. $\mathrm{O}$ outro período, cerca de $20 \%$ dos dados finais da série será para o processo de verificação do desempenho do modelo.

\subsection{Modelo hidrológico mensal determinístico de dois parâmetros (Xiong e Guo, 1999)}

\subsubsection{Evapotranspiração real mensal do modelo}

Os autores do modelo mensal de dois parâmetros sugerem a Equação 1, para estimar a evapotranspiração real mensal:

$$
E(t)=c \times E P(t) \times \tanh [P(t) / E P(t)]
$$

Em que, $\mathrm{E}(\mathrm{t})$ representa a evapotranspiração real, c é o primeiro parâmetro do modelo, $\mathrm{EP}(\mathrm{t})$ a evaporação do tanque classe $\mathrm{A}, \mathrm{P}(\mathrm{t})$ a precipitação e tanh a função tangente hiperbólica.

Neste trabalho, com a ausência dos dados de evaporação do tanque na região hidrográfica do Xingu, a evaporação real mensal foi calculada a partir da evapotranspiração potencial estimada pela equação de Thornthwaite e Mather (1955).

\subsubsection{Calculo da vazão mensal}

A vazão mensal $Q$ é relacionada com a quantidade de água no solo $\mathrm{S}$. A vazão Q é calculada como uma função tangente hiperbólica da quantidade de água no solo $\mathrm{S}$ através da Equação 2 :

$$
Q(t)=S(t) \times \tanh [S(t) / S C]
$$

Em que, $\mathrm{Q}(\mathrm{t})$ é a vazão mensal, $\mathrm{S}(\mathrm{t})$ quantidade de água no solo e SC é o segundo parâmetro utilizado no modelo, o qual é expresso em milímetros e representa a capacidade de campo da bacia. Segundo os autores do modelo este parâmetro está associado às características físicas e localização da bacia. Em regiões úmidas, com elevada precipitação os autores encontraram valores em torno de $1500 \mathrm{~mm}$.

Dada as séries de $\mathrm{P}(\mathrm{t})$ e $\mathrm{E}(\mathrm{t})$, a quantidade da água restante no solo será $[\mathrm{S}(\mathrm{t}-1)+\mathrm{P}(\mathrm{t})-\mathrm{E}(\mathrm{t})]$, com $\mathrm{S}(\mathrm{t}-1)$ sendo a quantidade de água no fim do mês $(\mathrm{t}-1)$ e no começo do mês t. A Equação (3) é usada então para calcular a vazão mensal
$\mathrm{Q}(\mathrm{t})$ como:

$$
\begin{aligned}
& Q(t)=[S(t-1)+P(t)-E(t)] \mathrm{x} \tanh \\
& \{[S(t-1)+P(t)-E(t)] / S C\}
\end{aligned}
$$

Finalmente, o índice de água no fim do mês t, isto é $\mathrm{S}(\mathrm{t})$, é calculado de acordo com a lei de conservação da água (Equação 4).

$S(t)=S(t-1)=P(t)-E(t)-Q(t)$

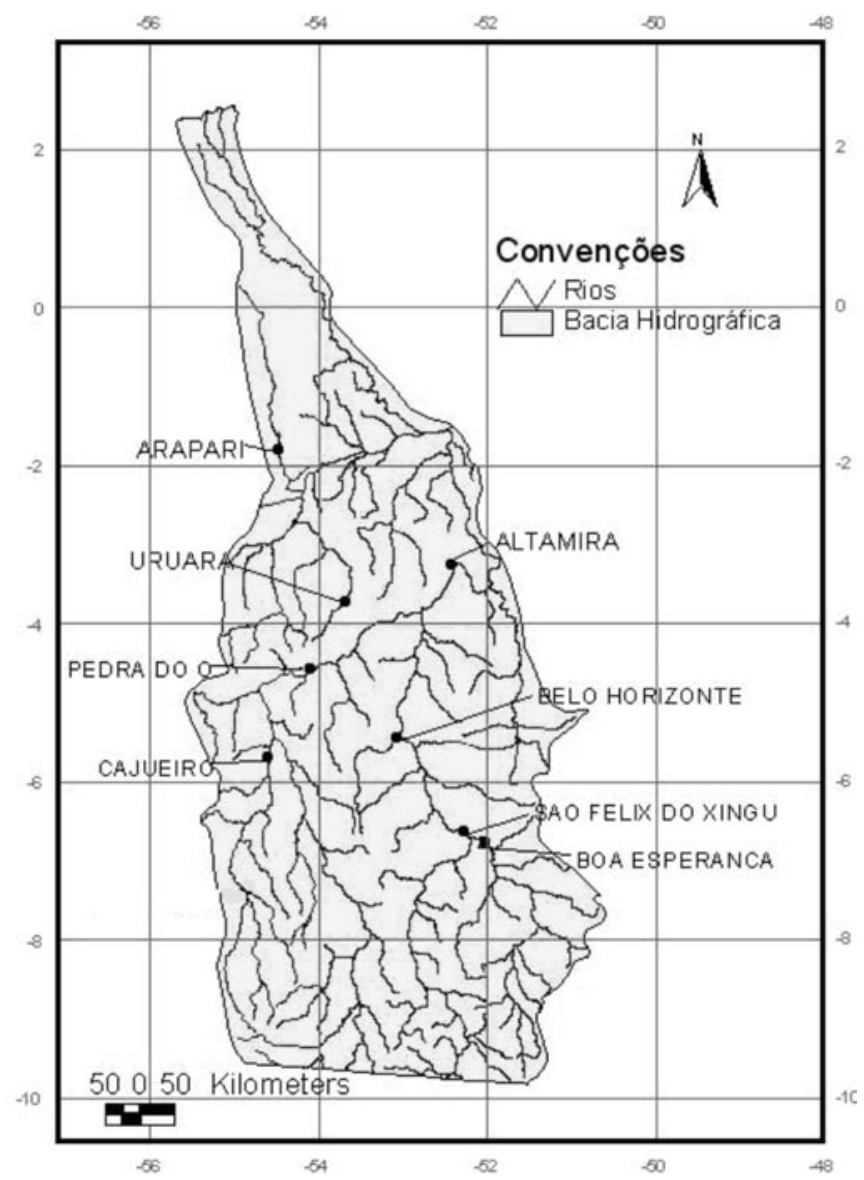

Figura 2 - Localização das estações fluviométricas e pluviométricas na região hidrográfica do Xingu/PA.

\subsubsection{Determinação da quantidade inicial de água no solo}

O valor de $\mathrm{S}(0)$ é assumido, considerando que um ano seja um período razoável para o ciclo de algumas variáveis hidrológicas, assim não deve ser muito diferente, por exemplo, entre dezembro de um ano e dezembro do ano seguinte, ou seja, $\mathrm{S}(12)$ e S(24) e assim por diante. Consequentemente, é razoável escolher $\mathrm{S}(0)$ como um valor médio da quantidade de água no solo S (Equação 5), considerando todos os meses do ano. 


$$
S(0) \approx \sum_{j=i}^{m} S j / m
$$

$\mathrm{Na}$ equação acima $\mathrm{S}(0)$ é a quantidade de água inicial no solo e $\mathrm{m}$ o número de meses da série de dados do período de calibração. Preliminarmente, o modelo proposto sugere que a quantidade inicial de água no solo $\mathrm{S}(0)$ seja um valor entre 150 e $200 \mathrm{~mm}$.

\subsubsection{Otimização dos parâmetros}

A otimização dos parâmetros do modelo foi feita através dos critérios de Nash-Sutcliffe (1970) descritos a seguir. Os valores otimizados dos parâmetros c e SC foram efetuados em duas etapas: primeiro otimizou-se os valores de c e SC de acordo com o primeiro critério de Nash-Sutcliffe $\left(\mathrm{Cl}_{\mathrm{NS}}\right)$, para obter bons ajustes de volumes máximos derivados de vazões simuladas. Segundo foi otimizado o parâmetro SC de acordo com o segundo critério de Nash-Sutcliffe $\left(\mathrm{C}_{\mathrm{NS}}\right)$, com o valor fixo de c, obtido no primeiro passo. Esse segundo passo da otimização pode ajudar na redução do efeito da inter-relação entre os dois valores dos parâmetros do modelo. Tendo em vista que o modelo hidrológico determinístico escolhido é extremamente parcimonioso, pois utiliza apenas dois parâmetros nas suas equações, foi possível aplicar ao modelo uma ferramenta do Excel, denominada "Solver", que utiliza o método conjugado ou método de Newton para calibrar os parâmetros c e SC.

\subsection{Modelos estocásticos ARIMA}

Para aplicação dos modelos ARIMA, é preciso inicialmente a compreensão de alguns conceitos estatísticos, destacando a análise de séries temporais, função de autocorrelação (ACF) e função de autocorrelação parcial (PACF), descritas abaixo. Uma descrição estatística mais detalhada pode ser encontrada em Brockwell \& Davis, 1991 e Granger \& Newbold, 1986.

Séries temporais referem-se a conjuntos de observações de uma dada variável ordenada no tempo, podendo ser descrita por características básicas como tendência e sazonalidade, apresentando uma dependência serial entre as variáveis. As observações de uma série temporal $\mathrm{Zt}$, em que $\mathrm{t}=1,2,3, \ldots, \mathrm{n}$, podem ser decompostas da seguinte forma:

$$
Z_{t}=T_{t}+S_{t}=a_{t}
$$

Em que, $\mathrm{T}_{\mathrm{t}}$ e $\mathrm{S}_{\mathrm{t}}$ representam tendência e sazonalidade da série, respectivamente, e at é uma variável aleatória de média zero e variância constante.

A função de autocorrelação (ACF) mede o grau de dependência entre os valores de uma série temporal em diferentes períodos. Os valores dos coeficientes de autocorrelação medem ainda a memória do processo estocástico, ou seja, mede o quanto um valor observado no tempo t é influenciado pelo valor observado no tempo t-k. Já a função de autocorrelação parcial (PACF) pode ser definida como a seqüência de correlações de uma série temporal $\left(Z_{t}\right.$ e $\left.Z_{t-1}\right),\left(Z_{t}\right.$ e $\left.Z_{t-2}\right),\left(Z_{t}\right.$ e $\left.Z_{t-3}\right)$ e assim por diante, com os efeitos de defasagens anteriores sobre $\mathrm{Zt}$ constantes. A função de autocorrelação parcial $\left(\phi_{\mathrm{kk}}\right)$ é aplicada aos resíduos da série.

O modelo estocástico de série temporal ARIMA é uma generalização dos modelos: autoregressivo (AR) e médiasmóveis (MA), definidos como segue:

$$
Z_{t}=\phi_{1} z_{t-1}+\ldots+\phi_{p} z_{t-p}+\varepsilon_{t}-\theta_{1} \varepsilon_{t-1}-\ldots-\theta_{q} \varepsilon_{t-q}
$$

Ou ainda:

$$
\left(1-\phi_{1} B-\ldots-\phi_{p} B^{p}\right) z_{t}=\left(1-\theta_{1} B-\ldots-\theta_{q} B^{q}\right) \varepsilon_{t}
$$

Em que B é o operador de defasagem $\left(\mathrm{Bz}_{\mathrm{t}}=\mathrm{z}_{\mathrm{t}-1}\right), \phi$ e $\theta$, são os parâmetros do modelo e $\varepsilon$ t o termo do erro (resíduos). $\mathrm{O}$ termo $\phi$ representa a parte autoregrresiva do modelo e o termo $\theta$ a parte médias móveis. Como as séries temporais apresentam componentes sazonais e não sazonais o modelo ARIMA pode ser escrito da seguinte forma:

$$
\begin{aligned}
& \left(1-\phi_{1} B-\ldots-\phi_{p} B^{p}\right)\left(1-\Phi_{1} B^{S}-\ldots-\Phi_{P S} B^{P S}\right) z_{t}= \\
& \left(1-\theta_{1} B-\ldots-\theta_{q} B^{q}\right)\left(1-\Theta_{1} B^{s}-\ldots-\Theta_{Q S} B^{Q S}\right) \varepsilon_{t}
\end{aligned}
$$

em que, $\Phi$ e $\Theta$ são prâmetros do modelo sazonal.

Diante de uma série temporal sazonal não-estacionária, para que um modelo ARIMA seja empregado é necessário remover a sazonalidade da série e transformá-la em uma série estacionária efetuando uma diferenciação sazonal. Contudo, às vezes, faz-se necessário, para aplicação do modelo, mais de uma diferenciação na série, a fim de atender os requisitos do modelo. Portanto, toma-se uma diferenciação na parte simples (d) e na parte sazonal (D). Como as séries temporais apresentam componentes sazonais e não sazonais o modelo ARIMA pode ser escrito da seguinte forma:

$$
\phi(B) \Phi\left(B^{s}\right)(1-B)^{d}(1-B)^{D} z_{t}=\theta(B) \Theta\left(B^{S}\right) \varepsilon_{t}
$$

Em que

$$
\begin{aligned}
& \phi(B)=\left(1-{ }_{11} B-\ldots-\phi_{p} B^{p}\right) ; \Phi\left(B^{S}\right)=\left(1-\Phi_{1} B^{S}-\ldots-\Phi_{P S} B^{P S}\right) ; \theta(B)= \\
& \left(1-\theta_{1} B-\ldots-\theta_{q} B^{q}\right) ; \Theta\left(B^{S}\right)=\left(1-\Theta 1 B^{S}-\ldots-\Theta_{Q S} B^{Q S}\right) .
\end{aligned}
$$

Para aplicação de modelos dos tipos AR e MAà uma série temporal, deve-se atender o requisito de estacionariedade nessa série, ou seja, média, variância e autocorrelação constantes. 
Essa estacionariedade da série pode ser analisada através dos gráficos de autocorrelograma ACF e PACF. Os modelos supracitados incluem os termos de defasagem autoregressiva $\mathrm{AR}(\mathrm{p})$ e de médias moveis MA(q). Dada a necessidade de tomar diferenças na série, o modelo é dito autoregressivo integrado de médias móveis - ARIMA (p, d, q). Para uma série temporal que apresenta sazonalidade o modelo ARIMA é do tipo (p, d, q) (P, $\mathrm{D}, \mathrm{Q})$ para as partes simples e sazonais, respectivamente.

O modelo original de Box e Jenkins envolve três estágios iterativos para seleção do modelo: (i) identificação do modelo; (ii) estimação do modelo e (iii) verificação de diagnósticos. A fase de identificação do modelo é a mais delicada do processo. Nessa fase se faz uma análise inicial da série e uma análise da ACF e PACF para identificar a ordem dos termos (p, d, q) e (P, D, Q). Outro ponto que deve ser analisado nessa etapa é a quantidade de parâmetros, pois quanto mais parâmetros utilizados no modelo mais erros poderão ser incorporados no processo. Com base no Principio da Parcimônia, deve-se tentar ajustar a parte autoregressiva (AR) e das médias móveis (MA) do modelo, com o menor número de ordens possível, portanto, deve-se evitar ajustar mais que duas ordens em ambas as partes do modelo.

Feita a análise da série e identificado o tipo de modelo ARIMA a ser usado, o próximo passo é a fase de estimativa dos parâmetros. Na modelagem ARIMA essa estimativa é feita por meio da função de máxima verossimilhança. A última fase é a da verificação do diagnóstico, que é feita através do termo do erro (resíduo), que deve constituir um processo de ruído branco, ou seja, apresentar uma distribuição normal com média zero e variância constante e sem correlação serial entre eles. A análise dos resíduos é importante para verificar se o modelo consegue capturar a dinâmica da série temporal em estudo. Feito os três processos com sucesso a previsão pode ser feita, caso contrário deve-se começar o ciclo novamente.

\subsection{Calibração e verificação dos modelos}

Para calibração e verificação dos modelos aplicados neste trabalho foram utilizados três critérios para mensurar o desempenho do modelo. O primeiro critério utilizado foi o critério de eficiência de Nash-Sutcliffe (1970) que é definido pela Equação 11, calculado em função do erro quadrático do volume de vazão observado e simulado pelos modelos aplicados.

$$
\mathrm{Cl}_{\mathbb{V}}=\frac{\sum_{\mathrm{i}}\left(\mathrm{Q}_{\mathrm{i}}-\overline{\mathrm{Q}}_{\mathrm{c}}\right)^{2}-\sum_{\mathrm{i}}\left(\mathrm{Q}_{\mathrm{i}}-\hat{\mathrm{Q}}_{\mathrm{i}}\right)^{2}}{\sum_{\mathrm{i}}\left(\mathrm{Q}_{\mathrm{i}}-\overline{\mathrm{Q}}_{\mathrm{c}}\right)^{2}} \times 100
$$

Em que $Q_{i}$ é a vazão observada, $\hat{Q}_{i}$ é a vazão simulada e $\bar{Q}$ é a vazão média da série observada. O valor esperado de C1NS no modelo é sempre próximo de 100, para uma boa simulação da série de vazão observada.

O segundo critério é a estimativa do erro relativo entre as séries de vazões observadas e simuladas. $\mathrm{O}$ valor de $\mathrm{C} 2 \mathrm{NS}$ é esperado ser próximo de zero para uma boa simulação das vazões observadas. Esse critério é definido pela Equação 12.

$$
\mathrm{C} 2_{\mathbb{N}}=\sum\left(\mathrm{Q}_{\mathrm{i}}-\hat{\mathrm{Q}}_{\mathrm{i}}\right) / \sum \mathrm{Q}_{\mathrm{i}} \times 100
$$

$\mathrm{O}$ terceiro critério $\left(\mathrm{C}_{\mathrm{NS}}\right)$ é aplicado para estimar o erro relativo entre a vazão máxima mensal observada e a vazão máxima mensal simulada, sendo definido pela Equação 13.

$$
\mathrm{C} 3_{\mathrm{v}}=\left(\mathrm{Q}_{\mathrm{m}}-\hat{\mathrm{Q}}_{\mathrm{m}}\right) / \mathrm{Q}_{\mathrm{m}} \times 100
$$

Em que $\mathrm{Q}_{\mathrm{m}}$ e $\hat{\mathrm{Q}}_{\mathrm{m}}$ representam as vazões máximas mensais observadas e simuladas, respectivamente.

\section{RESULTADOS}

Serão apresentadas, a seguir, as características dos parâmetros dos modelos e os resultados da aplicação do critério de Nash Sutcliffe para as vazões simuladas pelo modelo determinístico no período de calibração. Também, será apresentada a comparação entre os resultados obtidos pelos modelos e seus respectivos testes de desempenho no período de verificação.

\subsection{Modelo determinístico de dois parâmetros}

O modelo hidrológico determinístico mensal de dois parâmetros foi aplicado para simular as vazões mensais das estações da região hidrográfica do Xingu, para o período de calibração e verificação, utilizando médias mensais de precipitação e evapotranspiração potencial. Na metodologia sugerida os parâmetros c e SC foram calibrados de acordo com os critérios $C 1_{\mathrm{NS}}$ e $\mathrm{C} 2_{\mathrm{NS}}$ de Nash-Sutcliffe (1970). Os resultados estão descritos na Tabela 2 , bem como informações do período de calibração, valor inicial da quantidade de água no solo $\mathrm{S}(0)$, dados médios anuais de vazão $(\mathrm{Q})$, precipitação (P) e evapotranspiração potencial (ETP).

Pode ser visto na Tabela 2, que na calibração do modelo, o parâmetro c foi maior que um para todas as estações, como no modelo aplicado, a evapotranspiração real foi calculada com dados de evapotranspiração potencial, o modelo determinístico tende a superestimar a evapotranspiração real. O parâmetro SC variou entre $1700 \mathrm{~mm}$ e $2100 \mathrm{~mm}$ e a quantidade de água inicial no solo $\mathrm{S}(0)$, variou de 150 a 175 , conforme recomendado pelos autores do modelo. Os valores de $\mathrm{C} 1_{\mathrm{NS}}$ variam entre 44,40 para Arapari e 86,35 para São Felix do Xingu. Destacam-se 
Tabela 2 - Dados médios anuais, vazão (Q), precipitação (P) e evapotranspiração potencial (ETP) das estações estudadas e os resultados da calibração do modelo Determinístico

\begin{tabular}{lccccccccc}
\hline Estação & $\begin{array}{c}\mathrm{Q} \\
\left(\mathrm{m}^{3} / \mathrm{s}\right)\end{array}$ & $\begin{array}{c}\mathrm{P} \\
(\mathrm{mm})\end{array}$ & $\begin{array}{c}\text { ETP } \\
(\mathrm{mm})\end{array}$ & $\begin{array}{c}\text { Calibração } \\
(\text { Anos })\end{array}$ & $\mathrm{c}$ & $\mathrm{SC}$ & $\mathrm{S}(0)$ & $\begin{array}{c}\text { Determinístico } \\
\mathrm{C}_{\mathrm{NS}}\end{array}$ & $\mathrm{C}_{\mathrm{NS}}$ \\
\hline Altamira & 7912 & 2005 & 1655 & $1975-2000$ & 1,383 & 1800 & 150 & 72,90 & 4,09 \\
Arapari & 120 & 1684 & 1350 & $1972-1999$ & 1,536 & 2000 & 150 & 44,40 & $-0,01$ \\
Belo Horizonte & 5273 & 1837 & 1412 & $1976-1974$ & 1,249 & 2100 & 175 & 83,55 & $-0,18$ \\
Boa Esperança & 866 & 1968 & 1467 & $1976-1998$ & 1,259 & 2000 & 175 & 73,48 & 0,001 \\
Cajueiro & 825 & 1934 & 1391 & $1976-1998$ & 1,143 & 1800 & 150 & 78,51 & $-0,08$ \\
Pedra do Ò & 2762 & 1872 & 1403 & $1976-1990$ & 1,173 & 1700 & 175 & 78,56 & 25,11 \\
São Felix do & 4675 & 1982 & 1407 & $1975-1992$ & 1,357 & 1700 & 175 & 86,35 & 0,20 \\
Xingu & 34 & 1721 & 1375 & $1978-2001$ & 1,324 & 2000 & 150 & 48,31 & 0,01 \\
Uruara & & & & & & & & & \\
\hline
\end{tabular}

aqui as estações de Arapari e Uruara, que apresentam valores de C1NS menores que 50. Nas outras estações, os valores de C1NS ficaram acima de 50, com valor elevado de $\mathrm{C} 2_{\mathrm{NS}}, 25,11$ na estação de Pedra do Ó.

Durante o período de calibração do modelo hidrológico determinístico, verificou-se que pequenas variações nos valores do parâmetro SC não provocam grande influência nos resultados dos critérios $\mathrm{C}_{\mathrm{NS}_{\mathrm{N}}}$ e $\mathrm{C} 2_{\mathrm{NS}}$ de Nash-Sutcliffe. Isto se justifica, principalmente, devido à magnitude do valor do parâmetro em comparação com a quantidade de água no solo. O mesmo não foi verificado com relação ao parâmetro c do modelo.

\subsection{Modelo Estocástico ARIMA}

As ordens dos termos (p, d, q) (P, D, Q), para as partes simples e sazonais do modelo ARIMA, nas estações em estudo estão expostos na Tabela 3.

Tabela 3 - Ordens dos termos para o modelo estocástico ARIMA

\begin{tabular}{lll}
\hline Estação & $(\mathrm{p}, \mathrm{d}, \mathrm{q})$ & $(\mathrm{P}, \mathrm{D}, \mathrm{Q})$ \\
\hline Altamira & $(2,2,2)$ & $(1,1,1)$ \\
Arapari & $(2,2,2)$ & $(1,1,1)$ \\
Belo Horizonte & $(2,2,2)$ & $(1,1,1)$ \\
Boa Esperança & $(1,1,1)$ & $(1,1,1)$ \\
Cajueiro & $(1,1,1)$ & $(1,1,1)$ \\
Pedra do Ò & $(1,1,1)$ & $(1,1,1)$ \\
São Felix do Xingu & $(2,2,2)$ & $(1,1,1)$ \\
Uruara & $(1,1,1)$ & $(1,1,1)$
\end{tabular}

Após analise das funções ACF e PACF, nas estações em estudo, pode ser visto na Tabela 3 , que em todas as estações não foram necessários mais do que duas diferenças nos termos AR e MA, para a parte simples do modelo, e apenas uma diferença para a parte sazonal. Nesse sentido, a modelagem atende o princípio da parcimônia na aplicação do modelo estocástico ARIMA.

\subsection{Comparação dos modelos}

A Tabela 4 exibe os valores dos critérios de eficiência de Nash-Sutcliffe, escolhido para avaliar o desempenho dos modelos no período de verificação. Os hidrogramas e hietogramas de cada estação e os diagramas de dispersão entre as vazões observadas e simuladas pelos modelos são apresentados nas Figuras 3 a 18.

As estações de Altamira, Arapari, Belo Horizonte, Cajueiro, Pedra do Ó e São Felix do Xingu, apresentaram resultados satisfatórios em ambos os modelos para as simulações das vazões mensais (Figuras 3 a 16). De um modo geral, nessas estações as retas de regressão linear para os modelos aplicados, se aproximaram do ajuste ideal. Os valores dos coeficientes de determinação são melhores para o modelo estocástico ARIMA em todas as estações supracitadas. Em alguns casos, o modelo determinístico tende a subestimar as vazões mensais nos meses em que ocorreram eventos extremos de precipitação ou na fase crescente do período de chuvas. Em geral, todos os modelos estudados simularam muito bem as vazões mensais observadas em todas as estações da bacia durante o período seco.

Nas estações de Boa Esperança e Uruara, conforme visto na Tabela 4, os resultados dos critérios de Nash-Sutcliffe, 
para avaliação do desempenho do modelo no período de verificação, não foram satisfatórios para o modelo determinístico comparados com o modelo ARIMA. De um modo geral, o modelo determinístico subestimou as vazões mensais, de acordo com as Figuras 9 e 17 e com os gráficos de dispersão e reta de regressão linear, mostrados nas Figuras 10 e 18.

No geral, o modelo estocástico ARIMA foi o que melhor simulou as vazões mensais observadas em todas as estações da região hidrográfica do Xingu. Também foi o modelo que apresentou os melhores resultados para os critérios de Nash-
Sutcliffe, para avaliar o desempenho dos modelos no período de verificação; destacando-se as estações de Altamira, Belo Horizonte, Cajueiro, Pedra do Ò e São Felix do Xingu, conforme a Tabela 4.

O modelo determinístico de dois parâmetros desenvolvido por Xiong e Guo (1999) é bastante sensível a mudanças bruscas da precipitação. Valores extremos de precipitação influenciam fortemente a dinâmica do armazenamento de água no solo, afetando os resultados da simulação das vazões mensais para as estações da região hidrográfica estudada.

Tabela 4 - Resultados dos critérios de Nash-Sutcliffe, na avaliação de desempenho dos modelos

\begin{tabular}{lcccccc}
\hline \multirow{2}{*}{ Estação } & \multicolumn{3}{c}{ DETERMINÍSTICO } & \multicolumn{3}{c}{ ARIMA } \\
\cline { 2 - 7 } & $\mathrm{C} 1_{\mathrm{NS}}$ & $\mathrm{C}_{\mathrm{NS}}$ & $\mathrm{C}_{\mathrm{NS}}$ & $\mathrm{C}_{\mathrm{NS}}$ & $\mathrm{C}_{\mathrm{NS}}$ & $\mathrm{C} 3_{\mathrm{NS}}$ \\
\hline Altamira & 73,19 & $-10,62$ & 18,33 & 90,52 & 3,00 & $-7,23$ \\
Arapari & 78,01 & 15,57 & 36,18 & 83,56 & $-0,44$ & $-10,03$ \\
Belo Horizonte & 81,98 & $-1,28$ & $-9,06$ & 95,01 & 1,78 & 3,92 \\
Boa Esperança & 67,22 & 11,73 & 36,00 & 87,73 & 1,64 & 11,95 \\
Cajueiro & 77,57 & $-18,50$ & 9,06 & 93,73 & 3,23 & 13,34 \\
Pedra do Ò & 86,27 & $-10,75$ & 1,62 & 95,64 & 5,94 & $-3,93$ \\
São Felix do Xingu & 88,23 & 0,54 & 1,56 & 94,90 & 0,16 & 1,83 \\
Uruara & 53,61 & 22,07 & 35,63 & 86,49 & 8,05 & $-4,18$ \\
\hline
\end{tabular}

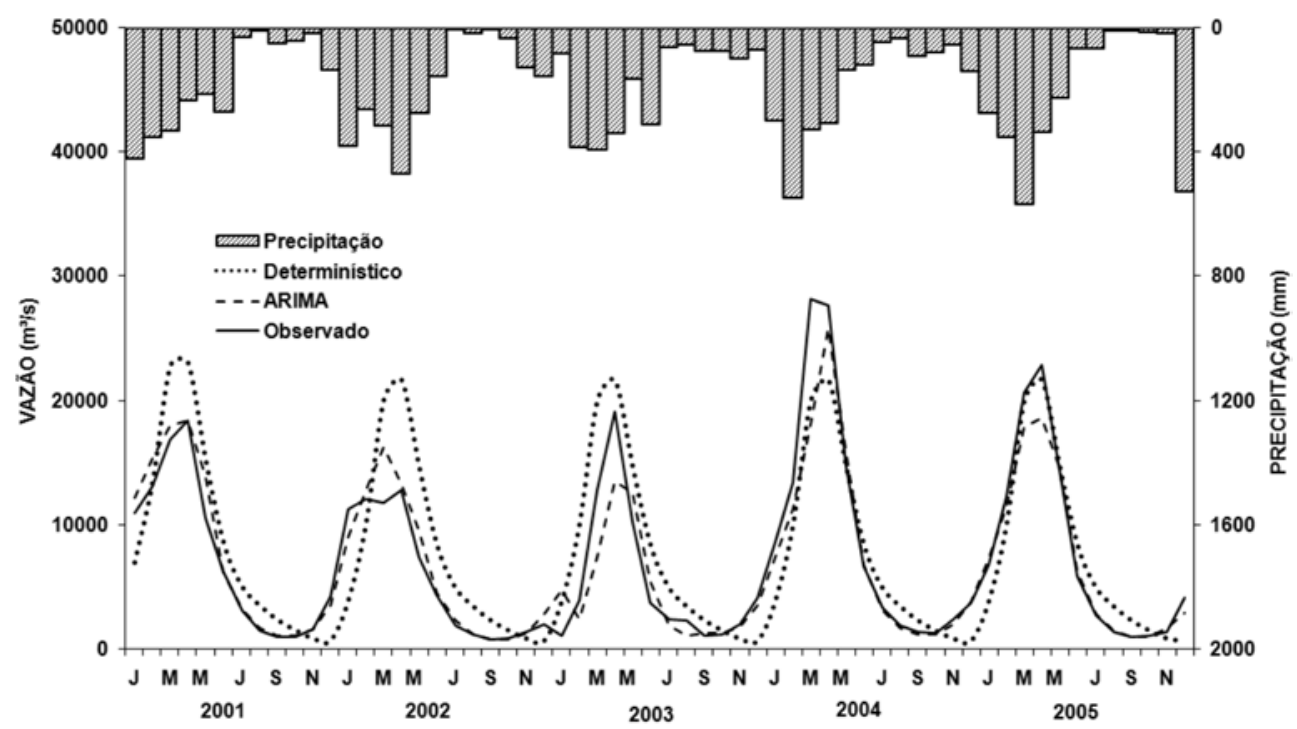

Figura 3 - Hidrogramas das vazões observadas e simuladas pelos modelos (linhas) e hietograma (colunas) em Altamira 

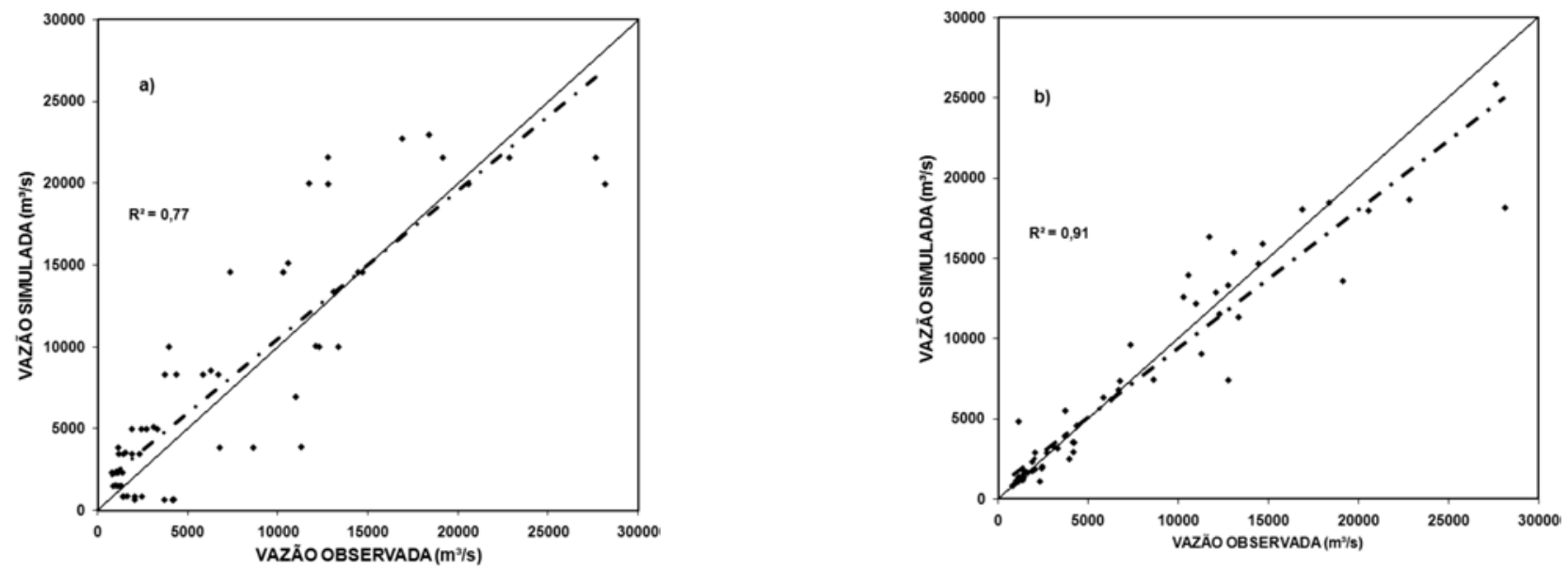

Figura 4 - Diagrama de dispersão, coeficiente de determinação e reta de regressão linear para as vazões simuladas pelos modelos: a) determinístico e b) ARIMA contra as vazões observadas em Altamira. As linhas tracejadas se referem à regressão linear e a contínua ao ajuste ideal

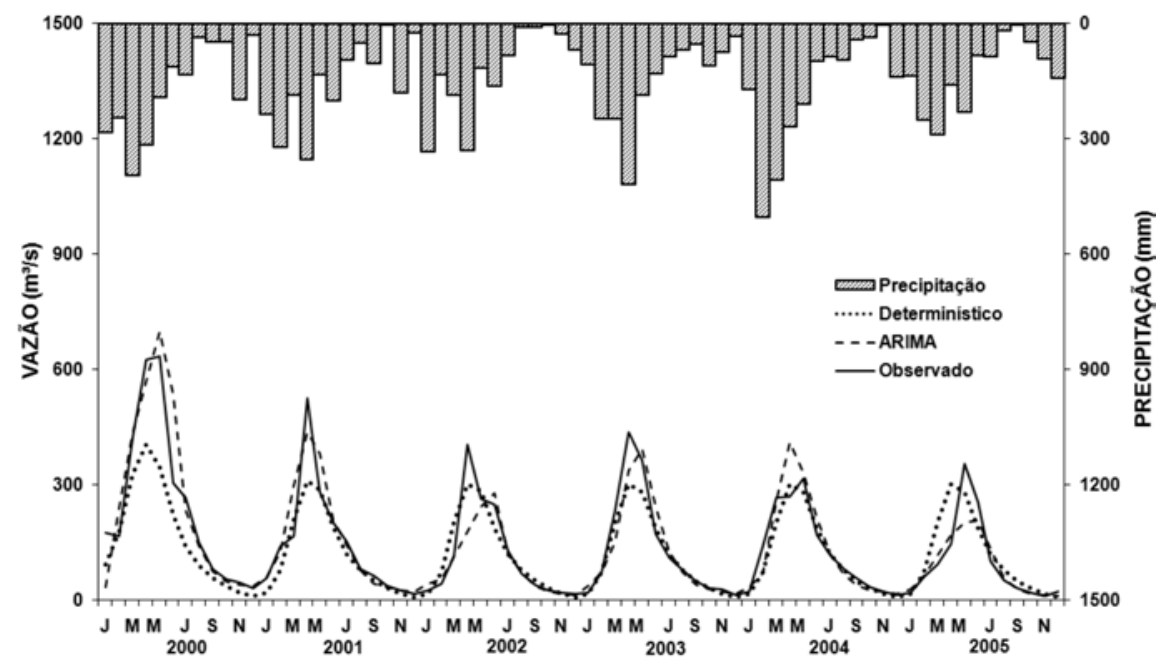

Figura 5 - Hidrogramas das vazões observadas e simuladas pelos modelos (linhas) e hietograma (colunas) em Arapari
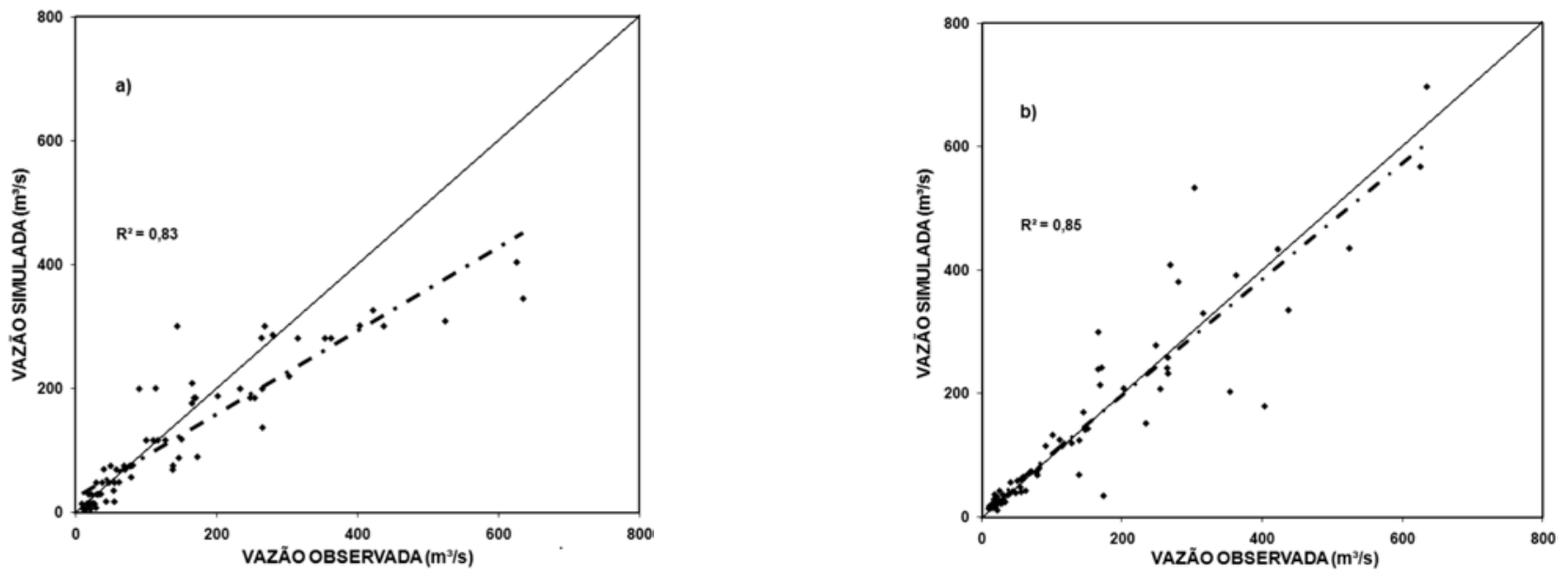

Figura 6 - Diagrama de dispersão, coeficiente de determinação e reta de regressão linear para as vazões simuladas pelos modelos: a) determinístico e b) ARIMA contra as vazões observadas em Arapari. As linhas tracejadas se referem à regressão linear e a contínua ao ajuste ideal 


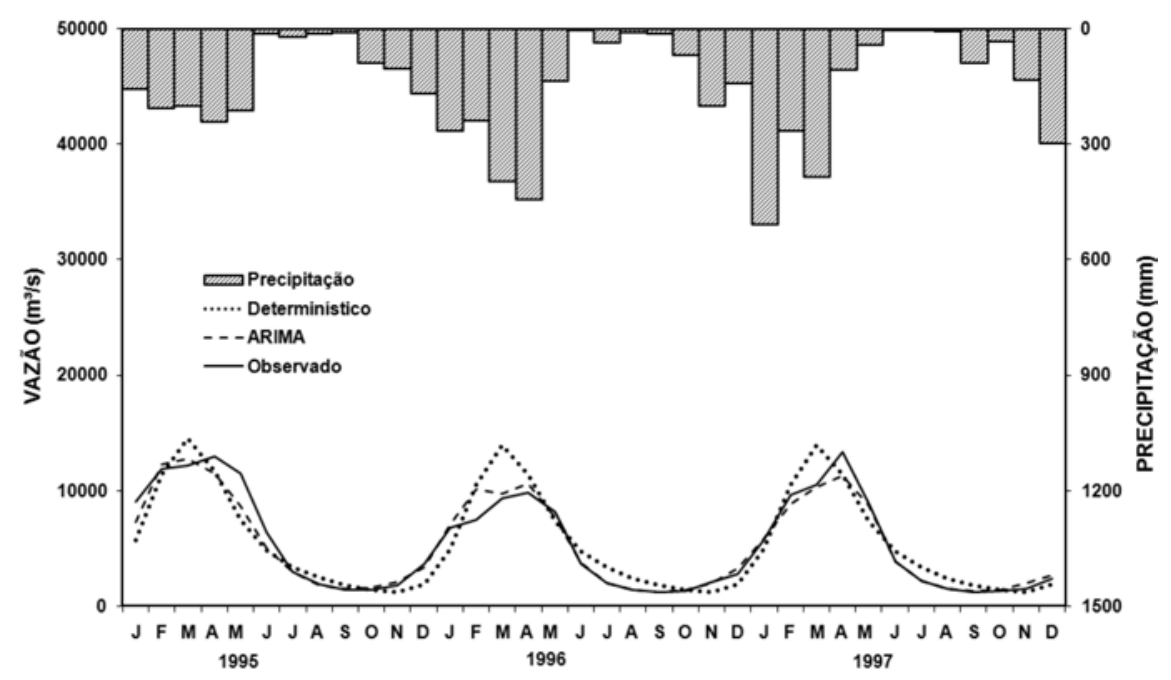

Figura 7 - Hidrogramas das vazões observadas e simuladas pelos modelos (linhas) e hietograma (colunas) em Belo Horizonte
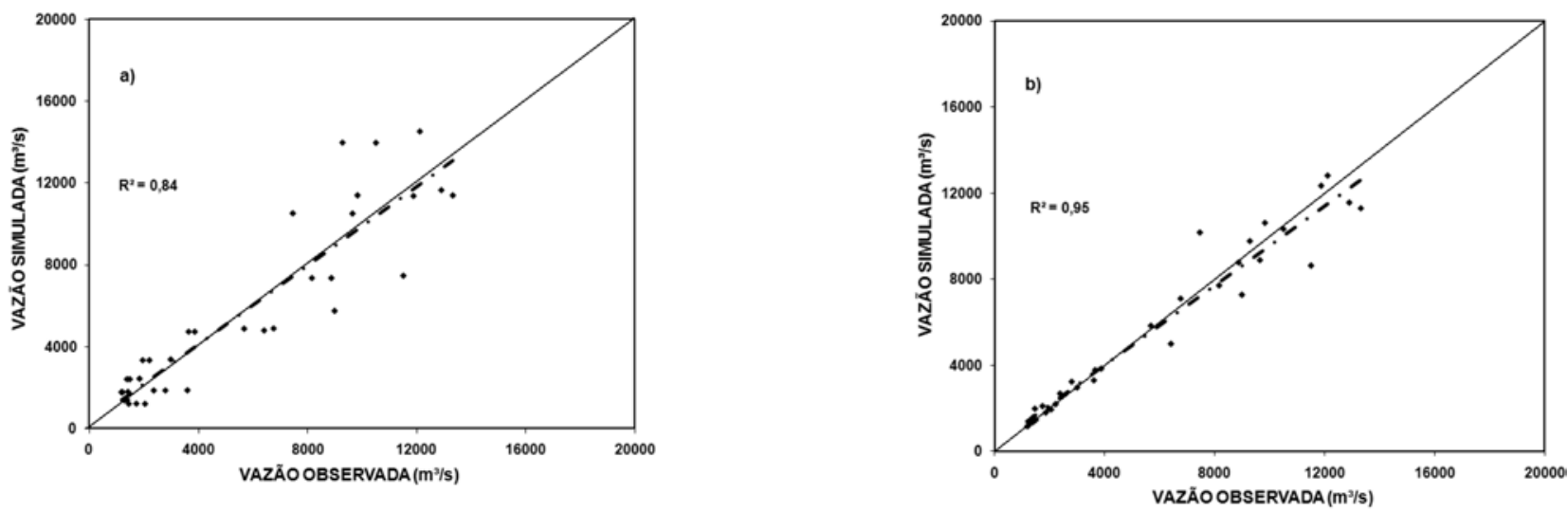

Figura 8 - Diagrama de dispersão, coeficiente de determinação e reta de regressão linear para as vazões simuladas pelos modelos: a) determinístico e b) ARIMA contra as vazões observadas em Belo Horizonte. As linhas tracejadas se referem à regressão linear e a contínua ao ajuste ideal

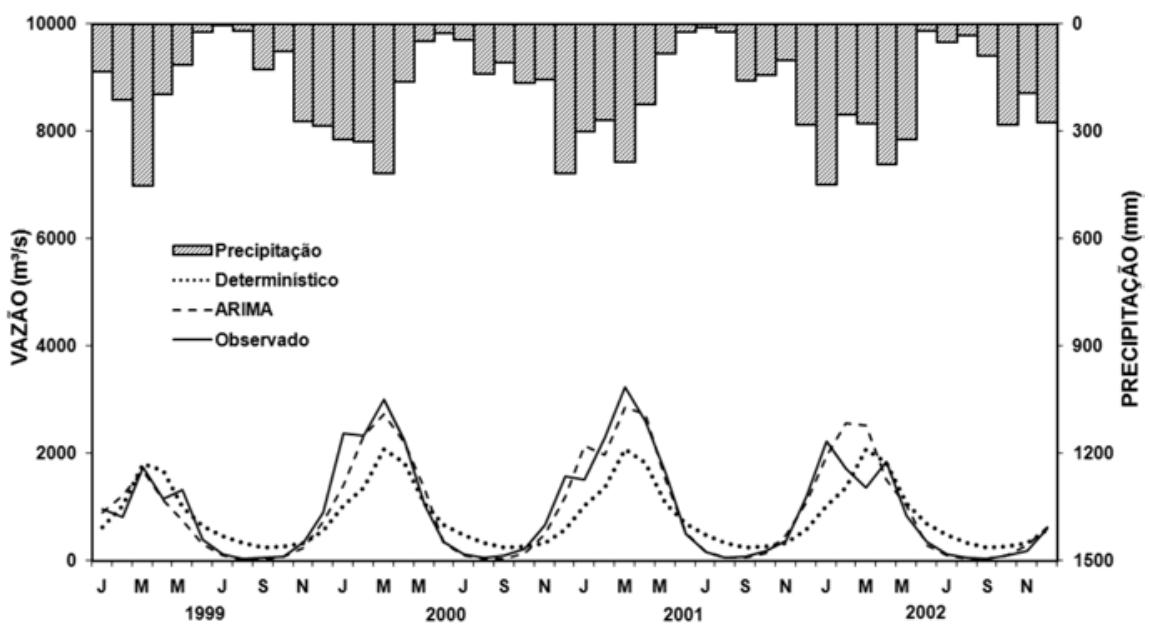

Figura 9 - Hidrogramas das vazões observadas e simuladas pelos modelos (linhas) e hietograma (colunas) em Boa Esperança 

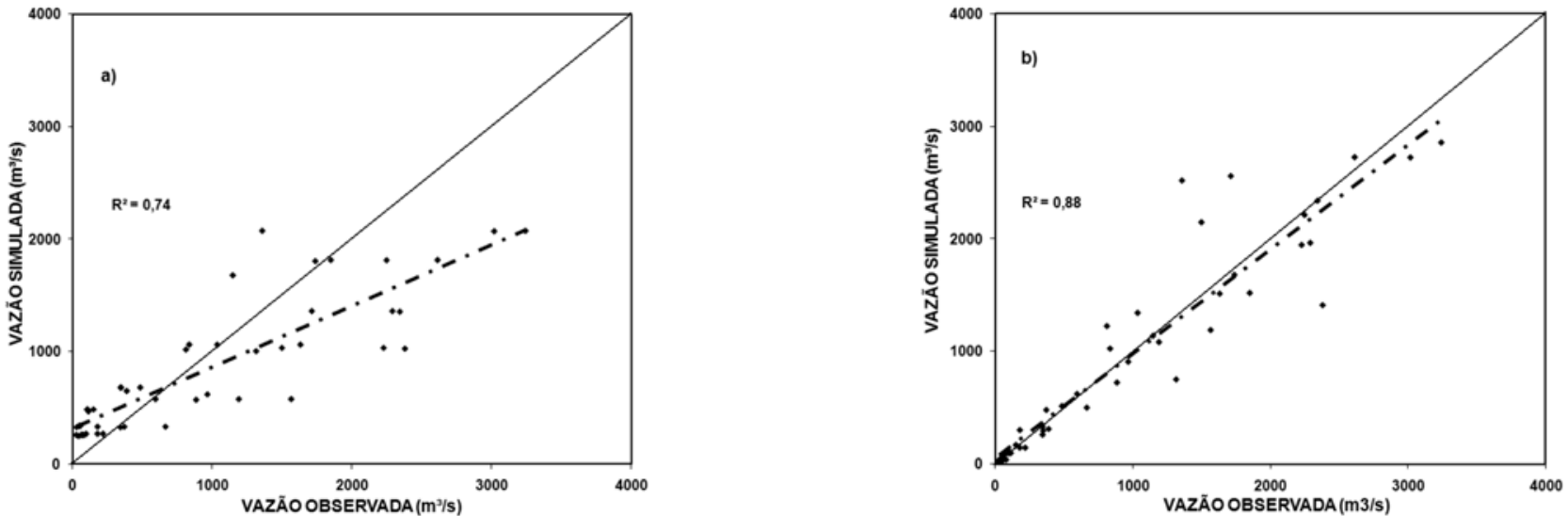

Figura 10 - Diagrama de dispersão, coeficiente de determinação e reta de regressão linear para as vazões simuladas pelos modelos: a) determinístico e b) ARIMA contra as vazões observadas em Boa Esperança. As linhas tracejadas se referem à regressão linear e a contínua ao ajuste ideal

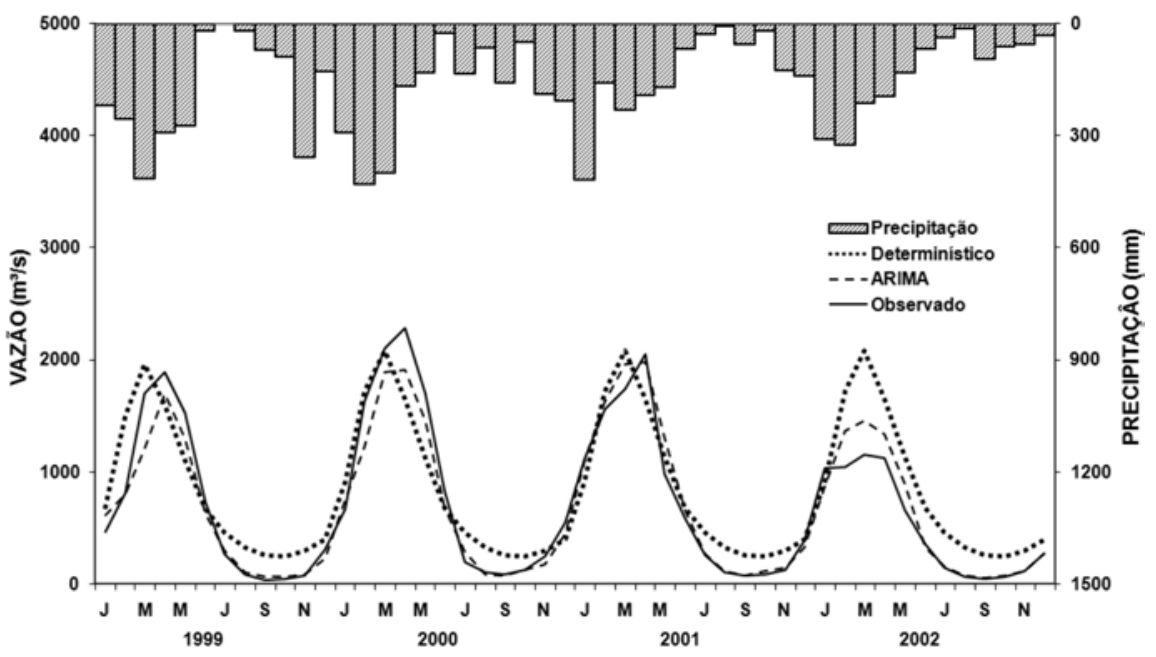

Figura 11 - Hidrogramas das vazões observadas e simuladas pelos modelos (linhas) e hietograma (colunas) em Cajueiro
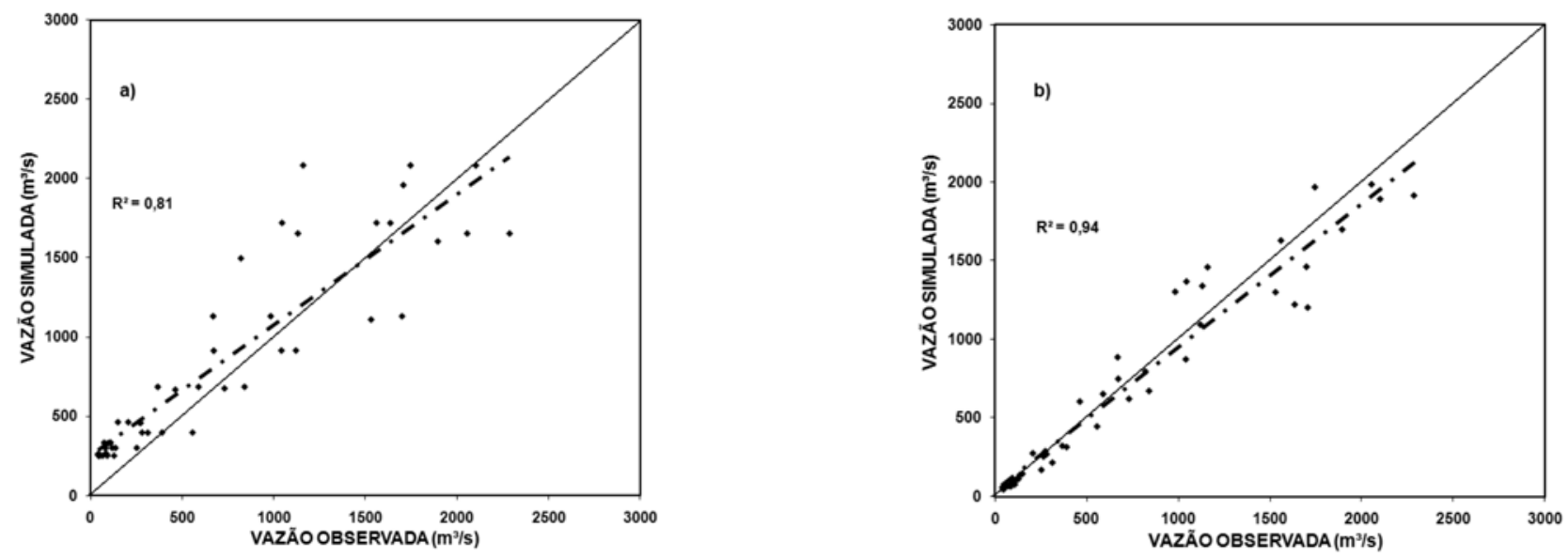

Figura 12 - Diagrama de dispersão, coeficiente de determinação e reta de regressão linear para as vazões simuladas pelos modelos: a) determinístico e b) ARIMA contra as vazões observadas em Cajueiro. As linhas tracejadas se referem à regressão linear e a contínua ao ajuste ideal 


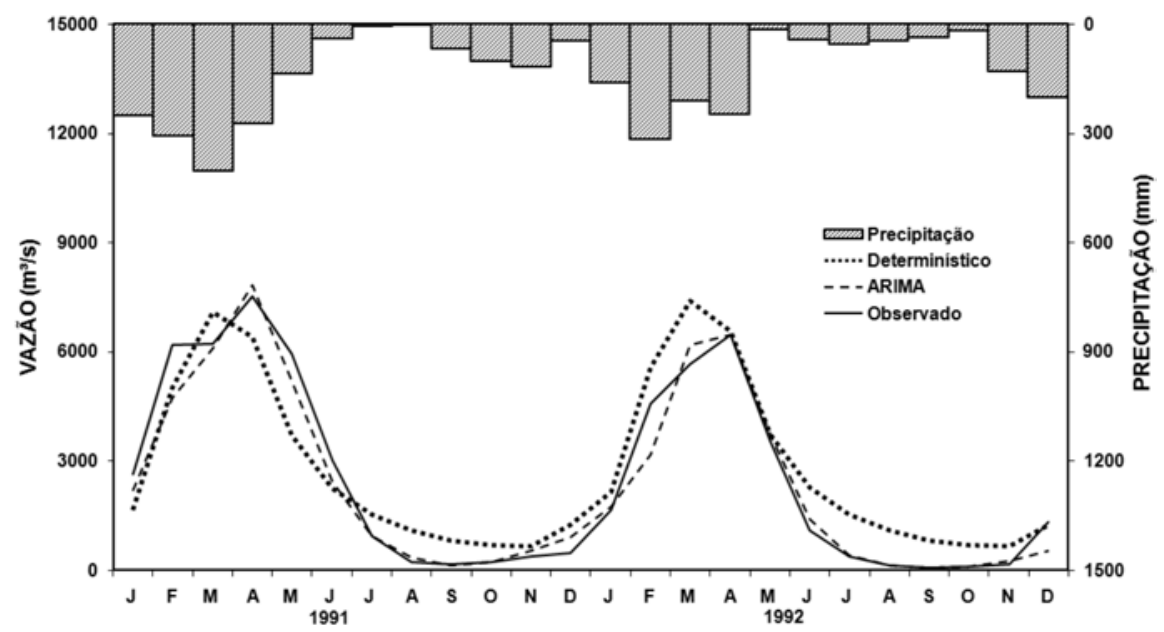

Figura 13 - Hidrogramas das vazões observadas e simuladas pelos modelos (linhas) e hietograma (colunas) em Pedra do Ó
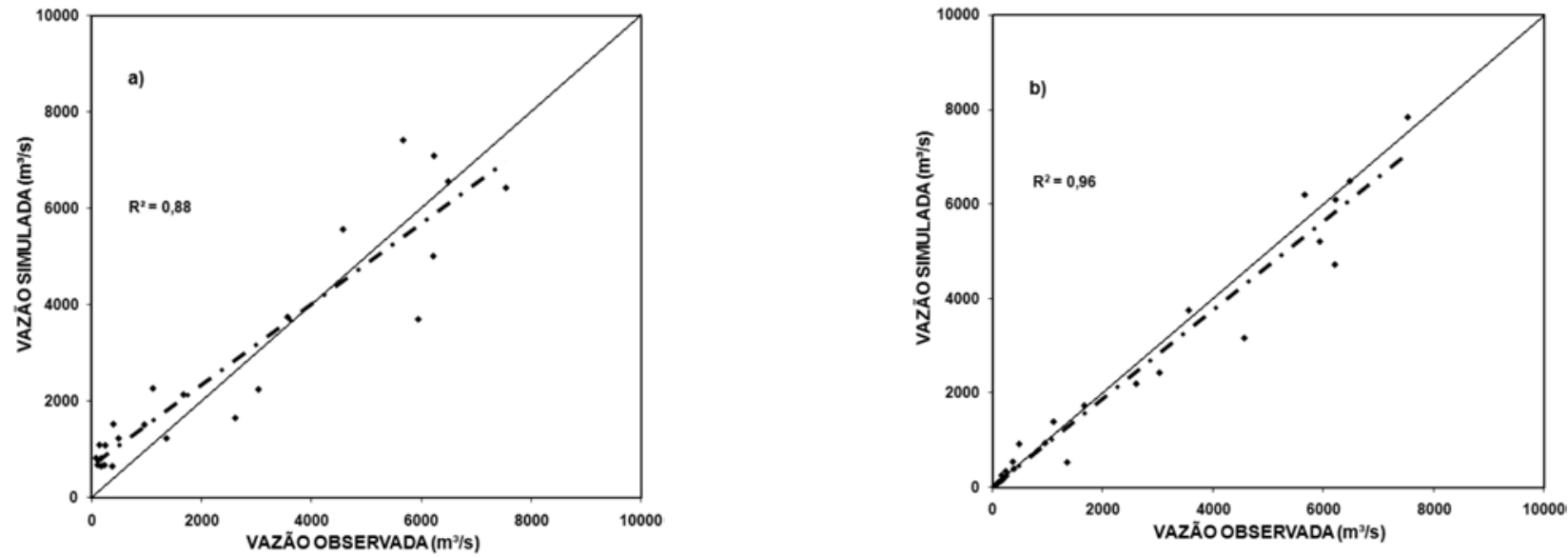

Figura 14 - Diagrama de dispersão, coeficiente de determinação e reta de regressão linear para as vazões simuladas pelos modelos: a) determinístico e b) ARIMA contra as vazões observadas em Pedra do Ó. As linhas tracejadas se referem à regressão linear e a contínua ao ajuste ideal

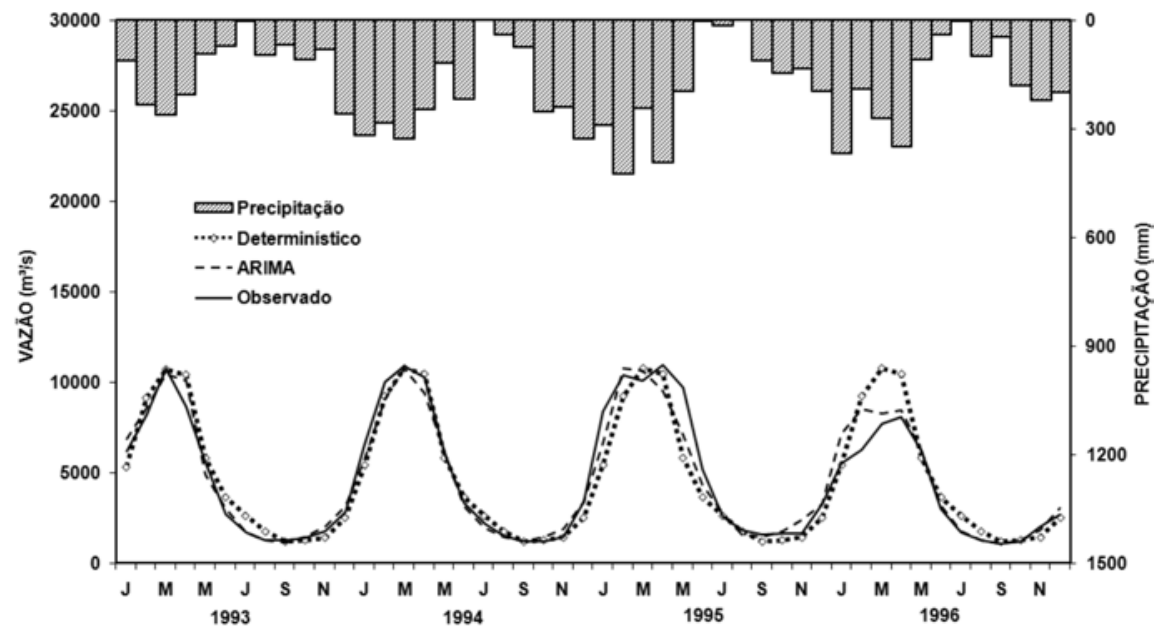

Figura 15 - Hidrogramas das vazões observadas e simuladas pelos modelos (linhas) e hietograma (colunas) em São Felix do Xingu 

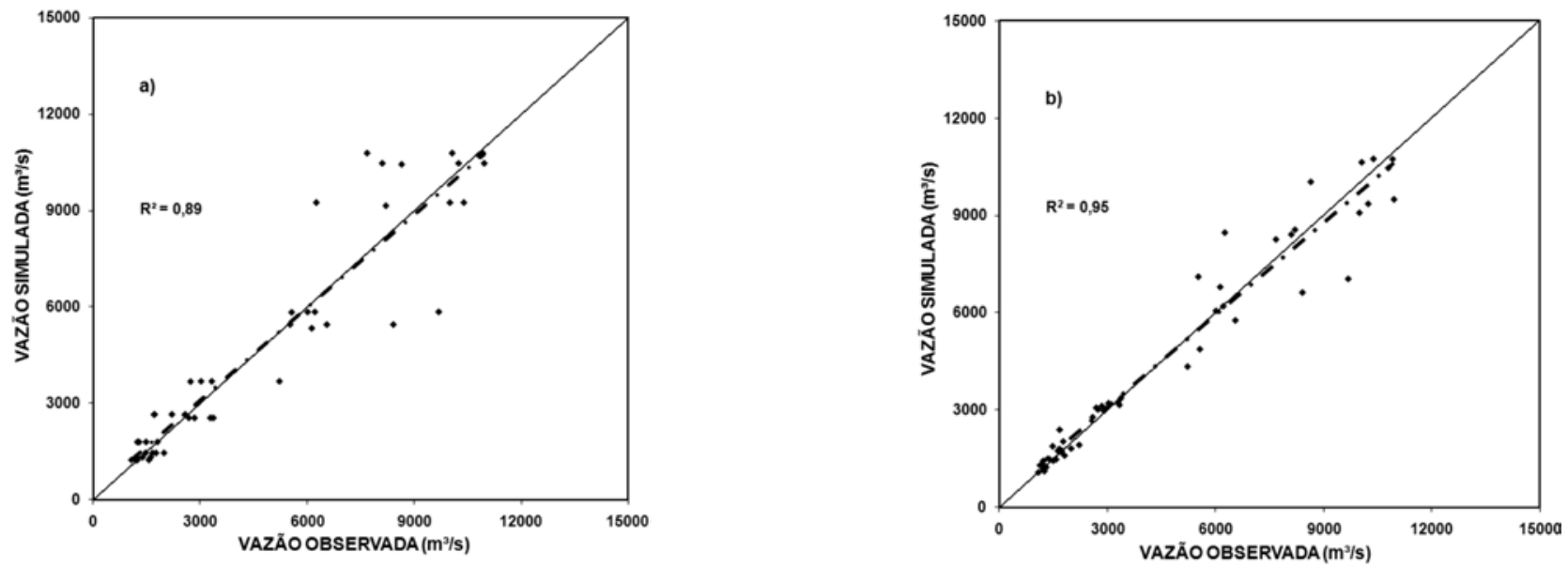

Figura 16 - Diagrama de dispersão, coeficiente de determinação e reta de regressão linear para as vazões simuladas pelos modelos: a) determinístico e b) ARIMA contra as vazões observadas em São Felix do Xingu. As linhas tracejadas se referem à regressão linear e a contínua ao ajuste ideal

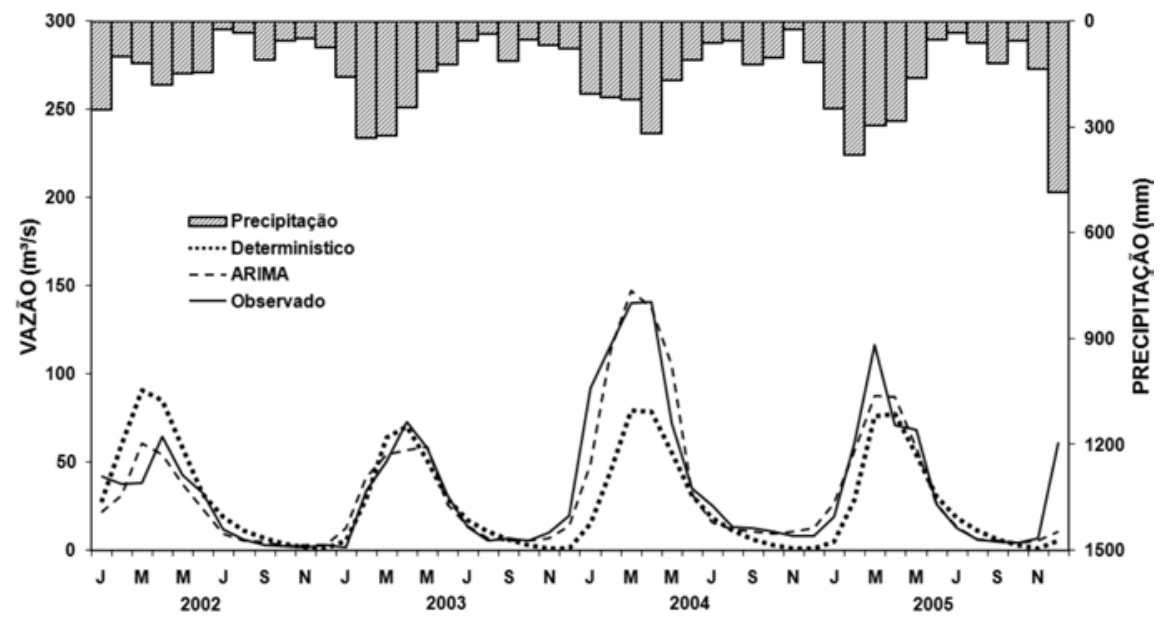

Figura 17 - Hidrogramas das vazões observadas e simuladas pelos modelos (linhas) e hietograma (colunas) em Uruara
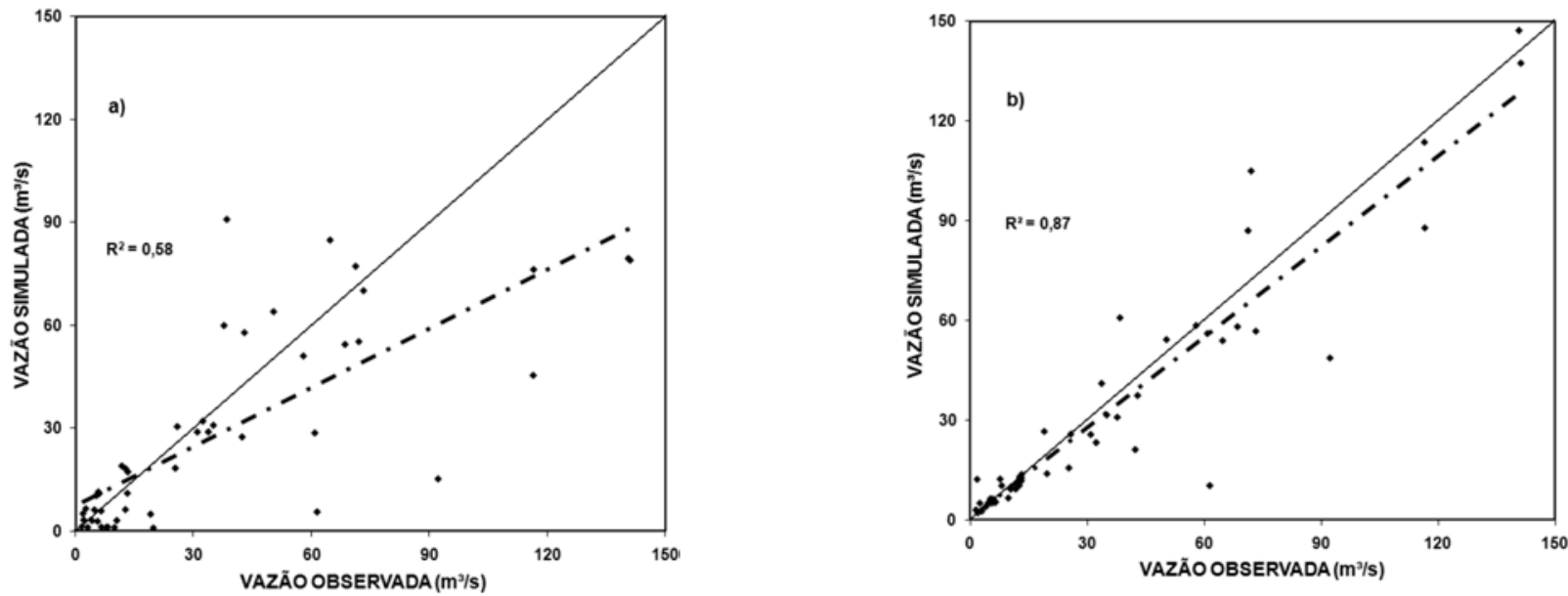

Figura 18 - Diagrama de dispersão, coeficiente de determinação e reta de regressão linear para as vazões simuladas pelos modelos: a) determinístico e b) ARIMA contra as vazões observadas em Uruara. As linhas tracejadas se referem à regressão linear e a contínua ao ajuste ideal 


\section{CONCLUSÕES}

O modelo hidrológico determinístico mensal de dois parâmetros, aplicado às vazões, possui estrutura simples e pode ser facilmente utilizado no planejamento e/ou gerenciamento dos recursos hídricos da região hidrográfica do Xingu, em especial na área de implantação da usina hidrelétrica de Belo Monte. Esse modelo mostrou-se bastante eficiente na simulação das vazões mensais, porém sensível a eventos extremos de precipitação, afetando fortemente o armazenamento de água no solo.

O modelo estocástico ARIMA apresentou melhores resultados na simulação das vazões mensais para todas as estações. O modelo ARIMA conseguiu capturar a dinâmica da série temporal na simulação das vazões mensais em todas as estações da região em estudo.

Os modelos estocástico e determinístico aplicados neste trabalho para simular vazões mensais no período seco, em todas as estações da região hidrográfica do Xingu, apresentaram resultados satisfatórios, porém devem ser aplicados com cautela no período chuvoso, visto que a maior parte dos eventos extremos de precipitação e consequentemente vazões de pico ocorrem nesse período.

\section{AGRADECIMENTOS}

O autor agradece ao Conselho Nacional de Desenvolvimento Científico e Tecnológico - CNPq, pela bolsa de Pós-graduação concedida pela Universidade Federal de Campina Grande - UFCG. Os autores agradecem também ao Instituto Nacional de Meteorologia - INMET e a Agência Nacional de Águas - ANA, pelo fornecimento de dados e apoio no desenvolvimento do trabalho.

\section{REFERÊNCIAS BIBLIOGRÁFICAS}

AGÊNCIA NACIONAL DE ÁGUAS (ANA). Inventario das estações fluviométricas e pluviométricas. Disponível em: $<$ www.ana.gov.br >. Acesso em abr. 2006.

BOX, G. E. P.; JENKINS, G. M. Time series analysis: forecasting and control. San Francisco: $2^{\mathrm{a}}$ ed., Holden Day, 1976.

BROCKWEEL, P. J.; DAVIS, R. A. Time series: theory and methods. New York: $2^{\mathrm{a}}$ ed., Springer - Verlag, 1991.

GALVÍNCIO, J.D.; SOUZA, F.A.S. Uso de modelos autoregressivo e médias móveis para geração de vazões médias mensais na bacia hidrográfica do alto São Francisco. In: CONGRESSO BRASILEIRO DE METEOROLOGIA, 12, 2002, Foz de Iguaçu. Anais... 2002, 1 CD-ROM.

GRANGER, C. W. J.; NEWBOLD, P. Forecasting economic time series. New York: $2^{\mathrm{a}}$ ed., Academic Press, 1986.
GUO, S. Impact of climatic change on hydrological balance and water resource systems in the Dongjiang Basin, China: Modeling and Management of Sustainable Basin-Scale Water Resource. Proceedings of a Boulder Symposium, LAHS Publication, n. 231, 1995.

GUO, S. Monthly water balance models for climate change impact study. Proceedings of First National Post-doctoral Conference, National Defense Industry Press, Beijing, $p$. 2034-2037, 1992.

INSTITUTO NACIONAL DE METEOROLOGIA (INMET). Normais Climatológicas. Disponível em: < http://www. inmet.gov.br/html/clima/mapas/?mapa $=$ tmax $>$. Acesso em mar. 2008.

KALNAY, E.; KANAMITSU, M.; KISTLER, R.; COLLINS, W.; DEAVEN, D.; GANDIM, L.; IREDELL, M.; SAHA, S.; WHITE, G.; WOLLEN, J.; ZHU, Y.; CHELIAH, M.; EBISUZAKI, W.; HIGGINS, W.; JANOWIAK, J. MO, K.C.; ROPELEWSKI, C.; WANG, J.; LEETMAN, A.; REYNOLDS, R.; JENNE, R.; JOSEPH, D. The NCEP/ NCAR 40 - year Reanalysis Project. Bulletin of the American Meteorological Society, v. 77, n. 3, p. 437-471, 1996.

KISTLER, R, ROBERT KISTLER, EUGENIA KALNAY, WILLIAM COLLINS, SURANJANA SAHA, GLENN WHITE, JOHN WOOLLEN, MUTHUVEL CHELLIAH, WESLEY EBISUZAKI, MASAO KANAMITSU, VERNON KOUSKY, HUUG VAN DEN DOOL, ROY JENNE AND MICHAEL FIORINO. The NCEP-NCAR 50-Year Reanalysis: Monthly Means CD-ROM and Documentation. Bulletin of the American Meteorological Society, v. 82, n. 2, p. 247-268, 2001.

LUCAS, E. W. M.; SOUSA, F. A. S.; MENEZES, R. H. N.; COSTA, R. F.; OLIVEIRA, L. L.; BARRETO, N. J. C. Variação espacial e temporal da precipitação na bacia hidrográfica do Xingu, Pará. In: CONGRESSO BRASILEIRO DE METEOROLOGIA, 13, 2006, Florianópolis. Anais...2006. 1 CD-ROM.

LUCAS, E. W. M.; SOUSA, F. A. S.; MENEZES, R. H. N.; COSTA, R. F.; OLIVEIRA, L. L. Regionalização da precipitação na bacia hidrográfica do Xingu, Pará. In: CONGRESSO BRASILEIRO DE METEOROLOGIA, 13, 2006, Florianópolis. Anais...2006. 1 CD-ROM.

NASH, J. E.; SUTCLIFF, J. River flow forecasting through conceptual models. Journal of Hydrology, v. 10, n.3, p. 282-290, 1970.

PERRIN, C.; MICHEL, C.; ANDRÉASSIAN, V. Improvement of a parsimonious model for Streamflow Simulation. Journal of Hydrology, v. 279, n.15, p. 275-289, 2003.

PERRIN, C.; MICHEL, C.; ANDRÉASSIAN, V. Does a large number of parameters enhance model performance? Comparative assessment of common catchments model 
structures on 429 catchments. Journal of Hydrology, v. 242, n. 3/4, p. 275-301, 2001.

THORNTHWAITE C.W., MATHER J.R., The water budget and its use in irrigation. In: Water, The Yearbook of Agriculture. Washington: US Department of Agriculture, 1955, p. 346358 .
TODINI, E. Rainfall-runoff modeling: Past, present and future. Journal of Hydrology, v. 100, p. n.1/3, 341-352, 1988.

TUCCI, C.E.M. Modelos Hidrológicos. Porto Alegre: Editora Universitária UFRGS, 1998.

XIONG, L.; GUO, S. A two-parameter monthly water balance model and its application. Journal of Hydrology, v. 216, n.1, p. 111-123, 1999. 